\title{
Lactobacillus brevis-based bioingredient inhibits Aspergillus niger growth on pan bread
}

\author{
Mariaelena Di Biase, Paola Lavermicocca, Stella Lisa Lonigro, Francesca Valerio \\ Institute of Sciences of Food Production, National Research Council, Bari, Italy
}

\begin{abstract}
Bread shelf life is generally compromised by fungi mainly belonging to Aspergillus and Penicillium genera, which colonise the surface of the product within few days from the production. The aim of this study was to select a Lactobacillus brevis-based bioingredient (LbBio) able to inhibit the growth of Aspergillus niger ITEM5132 on pan bread in order to prolong its shelf life. Four LbBio formulations, obtained by growing a selected $L$. brevis strain in a flour-based medium containing different carbon sources or acid precursors (fructose, LbBiol; fructose and maltose, LbBio2; $\alpha$-chetoglutaric acid, LbBio3; short-chain fructooligosaccharides, LbBio4), were evaluated for their content of organic acids (lactic, acetic, propionic, phenyllactic, 4-hydroxy-phenyllactic, valeric, isovaleric acids). The LbBio formulations were applied in yeast-leavened bread during bread-making trials and the resulting products were inoculated after baking with $A$. niger spore's suspension and the fungal growth was monitored during storage $\left(25^{\circ} \mathrm{C}\right.$ for 6 days). The formulation showing the highest inhibitory activity was separated by ultra-filtration method, and whole and fractions obtained were evaluated for their in vitro activity. The fraction showing the highest activity was further separated by gel-filtration and the resulting products
\end{abstract}

Correspondence: Francesca Valerio, Institute of Sciences of Food Production, National Research Council, via Amendola 122/0, 70126 Bari, Italy.

Tel.: +39.080 .5929369 - Fax: +39.080 .5929374 .

E-mail: francesca.valerio@ispa.cnr.it

Key words: anti-fungal activity, gel-filtration separation, organic acids, protein content, ultrafiltration separation.

Funding: this research was financed by Cluster CL.A.N. - Cluster Agrifood Nazionale: SO.FI.A. Sostenibilità della filiera agroalimentare italiana, CTN01_00230_450760.

Conference presentation: Meeting on Environmental Sustainability and Food Security, Potenza, Italy, 2014.

Received for publication: 10 July 2014.

Revision received: 19 September 2014.

Accepted for publication: 20 September 2014.

(C) Copyright M. Di Biase et al., 2014

Licensee PAGEPress, Italy

Italian Journal of Agronomy 2014; 9:614

doi:10.4081/ija.2014.614

This article is distributed under the terms of the Creative Commons Attribution Noncommercial License (by-nc 3.0) which permits any noncommercial use, distribution, and reproduction in any medium, provided the original author(s) and source are credited. were investigated for their protein content and in vitro inhibition.

The results from the bread-making trials performed using different formulations of LbBio showed a delay in fungal growth (1 day) respect to the bread not containing the bioingredient (control) or including calcium propionate $(0.3 \% \mathrm{w} / \mathrm{w})$. The formulation LbBio2, prepared with fructose and maltose $1 \%$ (w/vol), contained the highest amount of total organic acids, including phenyllactic and hydroxyl-phenyllactic acids, and reduced the visual spoilage of bread. This formulation was separated by ultra-filtration and fractions containing metabolites with molecular weight higher than $30 \mathrm{kDa}$ showed high inhibitory effect in the in vitro assay. In particular, the microfluidic analysis highlighted the presence of a protein with a molecular weight of $56 \mathrm{kDa}$ only in the active fraction. Further studies have to be done in order to identify the protein involved in the antifungal activity.

\section{Introduction}

Bread is one of the most important staple foods in the world and it is generally considered as a perishable commodity. The quality of bakery products is compromised by the contamination of raw materials by bacteria, yeast and moulds (Lavermicocca et al., 2003; Valerio et al., 2012; Legan and Voysey, 1991). Mould growth is the most common form of microbial spoilage in bread leading to huge economic losses (Legan, 1993) as well as reduced safety for consumers due to the production of toxic (mycotoxins) and allergenic (Visconti and Bottalico, 1983; Filtenborg et al., 1996; Latgè and Paris, 1991) compounds. Fungal spoilage of wheat bread is mainly due to Penicillium spp. and other fungi belonging to Aspergillus and Cladosporium genera.

In the course of the time, different strategies were proposed to preserve bread from moulds proliferation: addition of chemical compounds like benzoate, propionate and sorbate (Guynot et al., 2005) or preservation by using modified atmosphere (Karin and Per, 2005).

The European Directive on preservatives (1995/2/EC; European Commission, 1995) regulates and approves the use of sorbate $(0.2 \%$, $\mathrm{w} / \mathrm{w})$, propionate $(0.3 \%, \mathrm{w} / \mathrm{w})$ and ethanol (up to $2 \%, \mathrm{w} / \mathrm{w})$, as antifungal preservatives but their inhibitory efficacy depends on the fungal species contaminating the product.

Consumer's demand for reduced use of chemical preservatives prompted the need for alternative preserving strategies such as the use of bacteria naturally occurring in food. Actually, lactic acid bacteria (LAB) represent ideal candidates for this application, since their recognised generally regarded as safe status and their qualified presumption of safety status in the EU. Recently, LAB and their antimicrobial metabolites (such as organic and fatty acids, hydrogen peroxide, diacetyl and bacteriocins) are used in the bakery process to provide a natural preservation by reducing the presence of chemical preservatives (Lavermicocca et al., 2000, 2003; Ström, 2005; Dal Bello et al., 2007; Gerez et al., 2009). Furthermore, the use of LAB improves the physico-chemical and textural quality of the product by reducing the $\mathrm{pH}$ value of the dough and increasing the total titratable acidity 
(Wehrle et al., 1997; Katina et al., 2002; Komleni et al., 2010; Valerio et $a l ., 2014)$. In the latter study a $L$. brevis strain was selected to produce bioingredients efficient in improve yeast-leavened bread shelf life and its textural properties without affecting the leavening performance of S. cerevisiae (Valerio et al., 2014).

The genus Lactobacillus was frequently involved in the antifungal activity of LAB as recently reported by some authors (Stiles, 1996; Gerez et al., 2009, 2013; Ryan et al., 2011; Ryu et al., 2014; Black et al., 2013) and the majority of identified antifungal substances are organic acids, hydroxy fatty acids, hydrogen peroxide, reuterin and proteinaceous compounds. Lactic and acetic acids are the main products of the fermentation of carbohydrates by LAB that generally diffuse through the membrane of the target organisms (Axelsson, 1990) in their hydrophobic undissociated form and then reduce cytoplasmatic $\mathrm{pH}$ and stop their metabolic activities. Other acidic molecules recognised as antifungal compounds and produced by LAB are propionic, acetic and phenyllactic (PLA) acids. In particular, it was hypothesised that PLA may act in a synergy way with other antifungal substances also of proteinaceous nature (Lavermicocca et al., 2000; Magnusson and Schnürer, 2001; Ström et al., 2002; Gerez et al., 2009, 2013; Ryan et al., 2011). Actually, Magnusson and Schnürer (2001) reported that the antifungal metabolite produced by $L$. coryniformis subsp. coryniformis Si3 strain was a highly heat stable, small peptide of approximately 3 $\mathrm{kDa}$. Thus, probably, the LABs' inhibitory effect was not only due to the organic acid compounds but in agreement with other authors (Corsetti et al., 1998; Niku-Paavola et al., 1999; Ryan et al., 2011; Gerez et al., 2013) to synergistic activities between organic acids and peptides from the lactic acid bacterial fermentation.

The aim of the present study was to investigate the efficacy of metabolites produced by a selected $L$. brevis strain in yeast-leavened bread and the chemical nature of antifungal compounds.

\section{Materials and methods}

\section{Culture conditions and Lactobacillus brevis-based bioingredient preparation}

Lactobacillus brevis ITM18 was isolated from sourdough and belonged to the Collection of Institute of Sciences of Food Production National Research Council of Bari. For long-term storage, stock cultures were prepared by mixing $8 \mathrm{~mL}$ of a culture with $2 \mathrm{~mL}$ of Bacto glycerol (Difco, Becton Dickinson Co., Sparks, MD, USA) and freezing $1 \mathrm{~mL}$ portions of this mixture at $-80^{\circ} \mathrm{C}$. Culture was stored frozen $\left(-80^{\circ} \mathrm{C}\right)$ in MRS broth (0xoid Ltd., Basinstoke, UK) supplemented with $20 \%$ Bacto glycerol (Difco) and subcultured twice before use.

The bioingredient (LbBio) was prepared inoculating $1 \% \mathrm{vol} / \mathrm{vol}$ of an overnight $\left(37^{\circ} \mathrm{C}, 150 \mathrm{rpm}\right)$ L. brevis ITM18 culture in a flour-based medium (FBM, pH 6.2). Four LbBio compositions were obtained by a mixture of wheat flour $(100 \mathrm{~g})$, water $(500 \mathrm{~mL})$ : i) with $1 \%(\mathrm{w} / \mathrm{vol})$ fructose (Difco) (LbBiol); ii) with 1\% (w/vol) fructose and 1\% (w/vol) maltose (Difco) (LbBio2); iii) with $0.1 \%$ (w/vol) $\alpha$-chetoglutaric acid (Sigma Aldrich, Milan, Italy) (LbBio3); iv) with $1 \%$ (w/vol) short-chain fructooligosaccharides (scFOS, Sigma) (LbBio4). After incubation, each LbBio compositions were centrifuged $\left(10,000 \mathrm{rpm}, 10 \mathrm{~min}, 4^{\circ} \mathrm{C}\right)$ and the supernatants were further filtered with filter paper (Whatman N.4). As a control FBM incubated in the same conditions $\left(37^{\circ} \mathrm{C}, 150\right.$ rpm, $18 \mathrm{~h}$ ) but not inoculated with the $L$. brevis strain, was used. Each LbBio or the FBM were combined, instead of water amount, with ingredients of wheat pan bread.

\section{Fungal spore production}

The strain Aspergillus niger ITEM5132 was isolated from bread and belonged to the ITEM Collection of Institute of Sciences of Food Production - National Research Council of Bari. Three-days old spores of $A$. niger ITEM5132 were plated on potato dextrose agar (Difco) at $25^{\circ} \mathrm{C}$ with light/dark cycle $(12 / 12 \mathrm{~h})$, collected and suspended in Triton X-100 0.05\% (vol/vol) (Lavermicocca et al., 2003). Spores were counted in the Thoma chamber and $1 \mathrm{~mL}$ of the spore suspension $\left(10^{3}\right.$ spores/mL) was nebulised on pan bread samples after baking.

\section{Organic acid quantification in bioingredients}

The analysis of organic acids content (lactic, acetic, propionic, phenyllactic PLA, 4-hydroxy-phenyllactic OH-PLA, valeric, isovaleric acids) in the bioingredients and in FBM, were performed as reported in Valerio et al. (2014). Each bioingredient was centrifuged $(8422 \times \mathrm{g}, 10 \mathrm{~min})$ and the supernatant was freeze-dried, resuspended in high-performance liquid chromatography (HPLC) mobile phase $\left(0.005 \mathrm{~mol} / \mathrm{L} \mathrm{H}_{2} \mathrm{SO}_{4}\right.$, Fluka, Deisenhofen, Germany) and passed through a micro-concentrator (Ultracel-3 k, Amicon, Danvers, MA, USA) with a molecular-mass cut-off of $3000 \mathrm{Da}$, by centrifugation $\left(7000 \times \mathrm{g}, 2^{\circ} \mathrm{C}, 1 \mathrm{~h}\right)$. Solutions were loaded onto the column. The analysis of organic acids was performed by HPLC (AKTABasic10, P-900 series pump, Amersham Biosciences AB, Uppsala, Sweden), using a Rezex R0A-organic acid H+ (8\%) column $(7.80 \times 300$ mm, Phenomenex, Torrance, CA, USA) and a 3-channel UV detector (Amersham Biosciences 900) set at 210 and $220 \mathrm{~nm}$. The mobile phase was pumped at a flow rate of $0.6 \mathrm{~mL} / \mathrm{min}$ through the column heated to $70^{\circ} \mathrm{C}$. Quantification of the organic acids was performed by integrating calibration curves obtained from the relevant standards. The quantification limits were $21.211 \mathrm{mM}$ for lactic, $30.376 \mathrm{mM}$ for acetic, $1.984 \mathrm{mM}$ for propionic, $4.538 \mathrm{mM}$ for valeric, $1.286 \mathrm{mM}$ for isovaleric, $0.011 \mathrm{mM}$ for PLA and $0.009 \mathrm{mM}$ for OH-PLA acids.

\section{Bread-making trials}

The bread-making trials were performed to evaluate the efficacy of different LbBio compositions to inhibit the A. niger ITEM5132 growth on bread surface. Breads were made by kneading $350 \mathrm{~g}$ wheat flour, $5 \mathrm{~g}$ margarine, $5 \mathrm{~g}$ sugar, $10 \mathrm{~g}$ fresh baker's yeast (Saccharomyces cerevisiae) and $210 \mathrm{~mL}$ of tap water or of LbBio, or of FBM or of a calcium propionate water solution $\left(0.3 \% \mathrm{w} / \mathrm{w}\right.$ flour), in a mixer-cooking machine (Princess ${ }^{\circledR}$ Home Breadmaker, type 1936; Princess Household Appliance BV, Breda, Netherlands). Breads containing water or the FBM or calcium propionate were used as controls (Control 1, Control 2 and Control 3, respectively). The bread-making process included the following steps: $1^{\text {st }}$ kneading (10 min), $1^{\text {st }}$ leavening (20 min), $2^{\text {nd }}$ kneading (15 min), $2^{\text {nd }}$ leavening (20 min), forming ( $30 \mathrm{~s})$, last leavening $(55 \mathrm{~min})$, baking $(60 \mathrm{~min})$. The $\mathrm{pH}$ values after cooking were registered with $\mathrm{pH}$ meter for each bread that was in sterile conditions and stored in polyethylene bags after that $1 \mathrm{~mL}$ of $A$. niger ITEM5132 spores suspension $\left(10^{3}\right.$ spores $\left./ \mathrm{mL}\right)$ was nebulised on bread surface. Finally, loaves were stored at $25^{\circ} \mathrm{C}$ and daily examined until the appearance of $A$. niger growth on Control 1 bread. The breadmaking trial Test 1 was performed to evaluate the efficacy of different LbBio compositions (LbBio1, LbBio2, LbBio3, LbBio4) to inhibit the $A$. niger ITEM5132 growth on bread surface. Furthermore, a selected $L$. brevis bioingredient formulation was subjected to a ultrafiltration separation and whole and selected fractions were evaluated in bread-making trials (Test 2). In each test, water (Control 1), FBM (Control 2) and calcium propionate (Control 3 ) were used as controls.

\section{Lactobacillus brevis-based bioingredient by ultrafiltration and gel filtration}

The selected LbBio2 was subjected to ultrafiltration by using 
Labscale $^{\text {TM }}$ TFF System and the microfiltration membranes Pellicon ${ }^{\circledR}$ XL Device (Millipore Corp., Billerica, MA, USA). In particular, the bioingredient was separated in the following order: Biomax-5 (5 kDa), Biomax-30 (30 kDa) and Biomax-50 (50 kDa). The ultrafiltration products obtained from each microfiltration membrane were: permeate fractions (P5, P30, P50) and retain fractions (R5, R30, R50). All fractions were used in the in vitro agar assay inhibitory test.

The selected ultrafiltrated product (R30) was further separated by gel-filtration method. The R30 fraction was lyophilised, resuspended in phosphate buffer (50 mM-0.15 M NaCl, pH 7) and separated on a Superose 12 HR 10/30 column (GE Healthcare Bio-Sciences AB) with a chromatographic system (AKTA Basic 10, P-900 series pump) using a $500 \mu \mathrm{L}$ loop and a UV detector (Amersham Biosciences 900) set at 280 $\mathrm{nm}$ and $220 \mathrm{~nm}$. One $\mathrm{ml}$ of each fractions was collected. All fractions obtained by gel filtration were tested in in vitro microdilution test.

\section{Preliminary characterisation of antifungal compounds by microfluidic electrophoresis}

R30 fractions from gel filtration were analysed for the protein content by the Bradford assay (Bradford, 1976). The calibration curve was obtained using defined concentration of the bovine serum albumin [bovine serum albumin (BSA), fraction 5] (Bio-Rad) solution and its dilutions, as standards. Briefly, $10 \mu \mathrm{L}$ of each samples were diluted in $790 \mu \mathrm{L}$ of distilled water and $200 \mu \mathrm{L}$ of Bradford reagent. The protein concentration of samples was calculated with spectrophotometric method, measuring the absorbance at $595 \mathrm{~nm}$ and interpolated values obtained with standard curve of BSA. Only fractions containing proteins, concentrated by micro-concentrator at molecular-mass cut-off of 3000 Da (Ultracel 3-K, Amicon, Danvers, MA, USA), were analysed by sodium dodecylsulfatepolyacrylamide gel electrophoresis (SDS-PAGE). Protein sizing and analysis were done using an Agilent 2100 Bioanalyzer (Agilent Technologies $\mathrm{GmbH}$, Waldbronn, Germany) based on the microfluidic technology that minimises chemical and analytical procedures and shortens analysis time, automating the whole process. Chip-based protein analysis was performed according to the manufacturer's protocol using a Protein 200 Plus LabChip kit and dedicated Protein 200 Plus assay software (Expert). Proteins were separated electrophoretically and data were translated into individual electropherograms (molecular weight against fluorescence units). To obtain sizing of proteins, a Ladder, consisting of 11 different proteins with a lower limit marker at $6 \mathrm{kDa}$ and an upper limit marker at $210 \mathrm{kDa}$, was run on each chip to provide an internal calibration. Upper and lower markers are also incorporated in each unknown sample for direct comparison against the sizing ladder.

\section{In vitro inhibition assays}

To assess the inhibitory efficacy of ultrafiltrated and R30 fractions, the in vitro agar assay and the microdilution test were applied.

The in vitro agar test was performed in bread extract broth (BEB) agar. This medium was obtained as described by Pepe et al. (2003) using bread (Control 1) without preservative produced in laboratory. Briefly, $100 \mathrm{~g}$ of bread and $350 \mathrm{~mL}$ of distilled water were homogenised in stomacher Lab-Blender 400 for $2 \mathrm{~min}$; the suspension was then centrifuged (10,000 rpm, $10 \mathrm{~min}$ ), filtered (Whatman N.1) and the pH was adjusted to 6.8 with $\mathrm{NaOH} 1 \mathrm{M}$. BEB was supplemented with Agar Technical (16 g/L) (Difco) and sterilised $\left(121^{\circ} \mathrm{C}, 15 \mathrm{~min}\right)$. Each LbBio and ultrafiltrated samples $(200 \mu \mathrm{L})$ were plated on BEB agar. As control, $\mathrm{HCl}$-acidified water (CoI, pH 3.34) was used. Once the samples were dried on the plate, $100 \mu \mathrm{L}$ of $A$. niger ITEM5132 spore suspension (about $10^{2}$ spore $/ \mathrm{mL}$ ) were spread plated and plates were incubated at $25^{\circ} \mathrm{C}$ for $48 \mathrm{~h}$. The test was performed in duplicate. After incubation, germinating spores were counted at the stereoscope.

The inhibitory activity was reported as arbitrary units (AU), calculated as follow:

$$
1 \mathrm{AU}=\left(\mathrm{UFC}_{\mathrm{C}_{0} \mathrm{I}}-\mathrm{UFC}_{\mathrm{S}}\right)=100 \mathrm{UFC}
$$

were $\mathrm{UFC}_{\mathrm{C}_{0} \mathrm{I}}$ was the number of germinating conidia counted on plates containing $\mathrm{HCl}$-acidified water and $\mathrm{UFC}_{\mathrm{S}}$ was the number of germinating conidia on the plates containing samples. The activity percentage of each sample was calculated in comparison with activity obtained using LbBio2. The microdilution test was used to evaluate the antifungal activity of R30 fractions obtained by gel filtration. The assay was performed in sterile, disposable, multiwell microdilution plates $(96$ wells, IWAKI, Scitech Div., Asashi Techno Glass, Tokyo, Japan) as reported in Lavermicocca et al. (2003). Briefly, $50 \mu \mathrm{L}$ of each fraction were added to BEB inoculated with fungal spores (about $10^{4} \mathrm{spores} / \mathrm{mL}$ ) and not inoculated (blank). Inoculated wells were prepared in quintuplicate, and blank was prepared in triplicate. All microdilution plates were incubated in a humid chamber at $25^{\circ} \mathrm{C}$ for $72 \mathrm{~h}$. Fungal growth was measured by determining the optical density at $580 \mathrm{~nm}$ every $24 \mathrm{~h}$ with a spectrophotometer (LabsystemMultiskan MS, version 3.0, type 352 ). The inhibition percentage was calculated in comparison with fungal growth in control wells.

\section{Results}

\section{Organic acids in Lactobacillus brevis-based bioingredient formulations and antifungal efficacy in bread-making trials}

No trace of acetic, propionic, valeric and OH-PLA acids was found in the FBM but all bioingredients contained lactic, propionic, valeric and PLA acids (Table 1). The concentration of lactic and acetic acid, PLA and OH-PLA produced by the selected $L$. brevis ITM18 strain in the bioingredient containing fructose and maltose as carbon source, named LbBio2, was found to be significantly higher $(\mathrm{P}>0.05)$ than in the other

Table 1. Organic acid content in different L. brevis-based bioingredient compositions.

\begin{tabular}{|c|c|c|c|c|c|c|c|c|}
\hline & & & & centrati & & & & \\
\hline & Lactic & Acetic & Propionic & Valeric & Isovaleric & PLA & OH-PLA & Total content \\
\hline FBM & 49.499 & $\mathrm{~A}^{\mathrm{a}}$ & $-\mathrm{a}$ & $\mathrm{a}^{\mathrm{a}}$ & 1.36 & 0.021 & $\mathrm{a}^{\mathrm{a}}$ & 50.880 \\
\hline LbBiol & 71.451 & -a & 7.153 & 17.407 & 2.23 & 0.029 & -a & 98.270 \\
\hline LbBio2 & 71.644 & 58.340 & 10.969 & 15.363 & 5.48 & 0.051 & 0.032 & 161.879 \\
\hline LbBio3 & 56.320 & $-\mathrm{a}$ & 8.558 & 8.356 & $-\mathrm{a}$ & 0.024 & $-\mathrm{a}$ & 73.258 \\
\hline LbBio4 & 66.678 & $-\mathrm{a}$ & 11.710 & 14.926 & 5.32 & 0.033 & _a $^{\mathrm{a}}$ & 98.667 \\
\hline
\end{tabular}

PLA, phenyllactic acid; OH-PLA, 4-hydroxy-phenyllactic acid; FBM, flour-based medium; LbBio, L. brevis-based bioingredient composition. ${ }^{\mathrm{a}}<\mathrm{LOQ}$. The quantification limits (LOQ) were $21.211 \mathrm{mM}$ for lactic, $30.376 \mathrm{mM}$ for acetic, $1.984 \mathrm{mM}$ for propionic, $4.538 \mathrm{mM}$ for valeric, $1.286 \mathrm{mM}$ for isovaleric, $0.011 \mathrm{mM}$ for PLA and $0.009 \mathrm{mM}$ for OH-PLA acids. 
bioingredients. In particular only in this composition L. brevis produced acetic and OH-PLA acids. Moreover in LbBio2 a greater concentration of total acid content than other bioingredients was observed. Lactic acid was produced at concentration by $49.499 \mathrm{mM}$ (FBM) to $71.644 \mathrm{mM}$ (LbBio2), instead the acetic acid was produced only in LbBio2 (58.340 $\mathrm{mM})$. Both PLA and OH-PLA were found to be produced only in LbBio2. The organic acid content in FBM not inoculated with $L$. brevis was probably due to the presence of an endogenous microbial population in the flour used to produce the medium. In bread-making Test 1 the four bioingredients (LbBio1, LbBio2, LbBio3, LbBio4) were compared to Control bread 1 and 2 containing water or calcium propionate $(0.3 \%$, $\mathrm{w} / \mathrm{w}$ flour), respectively. All tested bioingredients allowed to obtain bread $\mathrm{pH}$ values lower than control breads (Table 2). A 1 day delay (respect control bread 1) in the appearance of $A$. niger growth was observed in all bread samples containing bioingredients, showing an inhibitory efficacy comparable to that of propionate (data not shown). In particular, LbBio2 caused a delay of fungal growth and a lower fungal colonisation indicating an interesting preserving ability and a thermal stability of the active metabolites during the bread cooking.

\section{Preliminary characterisation of antifungal compounds}

Fractions of LbBio2 were separated by ultrafiltration with membrane cut-off of $5 \mathrm{kDa}, 30 \mathrm{kDa}$ and $50 \mathrm{kDa}$ to isolate the antifungal compounds. Table 3 showed that the permeate P5, containing molecules with molecular mass lower than $5 \mathrm{kDa}$, not influenced $A$. niger growth, instead the antifungal efficacy occurred in R5 fraction, characterised by compounds with weight $>5 \mathrm{kDa}$; therefore $\mathrm{R} 5$ was further ultrafiltrated with membrane cut-off of $30 \mathrm{kDa}$. The resulting R30 fraction was ultrafiltrated with membrane cut-off of $50 \mathrm{kDa}$. Fractions R30, P30, R50 e P50 showed a distributed anti-fungal activity. In particular, R30 and R50 were efficient in inhibiting $A$. niger growth, indicating that active molecules of LbBio 2 had a molecular mass $>30 \mathrm{kDa}$. Moreover, preliminary results showed that antifungal activity was not modified after thermal treatment of fractions, confirming a high thermal stability (data not shown).

The most active fraction (R30, Table 3) was used in comparison with unfractionated LbBio2 in a bread-making trial (Test 2). The selected fraction (Figure 1D) confirmed its efficacy showing preserving performance similar to that of propionate-containing bread (Figure 1B).

Gel-filtration method was applied to R30 and fractions were further analysed by SDS-PAGE gel electrophoresis and tested for the antifungal activity. Fractions from 7 to 24 contained proteins and were tested by microdilution test on $A$. niger. The antifungal activity was observed in fractions from 7 to 13 and from 21 to 24 at percentage ranging from $47.4 \%$ to $100 \%$ (Table 4 ). In particular, fractions from 8 to 10 showed $100 \%$ inhibition of fungal growth, while the antifungal activity of fractions from 14 to 20 was not observed. The remaining fractions showed intermediate values of inhibitory activity (Table 4).

Furthermore, the SDS-PAGE microfluidic electrophoresis performed on fractions from 10 to 24 ,indicated that the active fractions $(10,11,20$, $21,22)$ contained proteins at molecular mass ranging from 15 to 63 $\mathrm{kDa}$. In particular, $29 \%$ of the protein content of the active sample R30 was represented by a protein with molecular mass of about $56 \mathrm{kDa}$.

\section{Discussion and conclusions}

Several strategies have been developed to extend the bread shelf-life generally compromised by fungal contamination which causes economic losses to baking industries and improve its quality (Legan and Voysey, 1991; Valerio et al., 2014). The increased interest in biopreser-
Table 2. $\mathrm{pH}$ values of bread samples containing the four $L$. brevis-based bioingredient compositions (LbBio), water (Control 1) or flour-based medium (Control 2 ) or calcium propionate $(0.3 \%$ w/w flour, Control 3), instead of the LbBio.

\begin{tabular}{lc} 
Bread sample & Bread pH \\
LbBiol & 4.59 \\
LbBio2 & 4.58 \\
\hline LbBio3 & 4.57 \\
LbBio4 & 4.51 \\
\hline Control 1 (water) & 5.70 \\
Control 2 (FBM) & 5.10 \\
\hline Control 3 (propionate) & 5.17 \\
\hline
\end{tabular}

LbBio, L. brevis-based bioingredient composition; FBM, flour-based medium.

Table 3. Inhibitory efficacy of $L$. brevis-based bioingredient fractions obtained by ultrafiltration against $A$. niger ITEM5132 growth. The inhibitory activity is reported as arbitrary units. The activity percentage of each sample was calculated in comparison with activity obtained using LbBio2.

\begin{tabular}{lcc} 
Sample & \multicolumn{3}{c}{ A. niger ITEM5132 } & Inhibition (\%) \\
LbBio2 & 3051 & - \\
R5 & 2269 & 74.4 \\
\hline P5 & 0 & 0 \\
R30 & 3051 & 100 \\
\hline P30 & 1080 & 35.3 \\
R50 & 1852 & 61 \\
\hline P50 & 800 & 26.2 \\
\hline
\end{tabular}

$\mathrm{AU}$, arbitrary units; LbBio, L. brevis-based bioingredient composition. *AU were obtained using the following formula: $1 \mathrm{AU}=\left(\mathrm{UFC}_{\mathrm{C}_{0}} \mathrm{I}-\mathrm{UFC}_{\mathrm{S}}\right)=100 \mathrm{UFC} ; \mathrm{UFC}_{\mathrm{C}_{0}} \mathrm{I}$ : number of germinating conidia counted on plates containing $\mathrm{HCl}$-acidified water and $\mathrm{UFC}_{\S}$ was the number of germinating conidia on the plates containing samples.
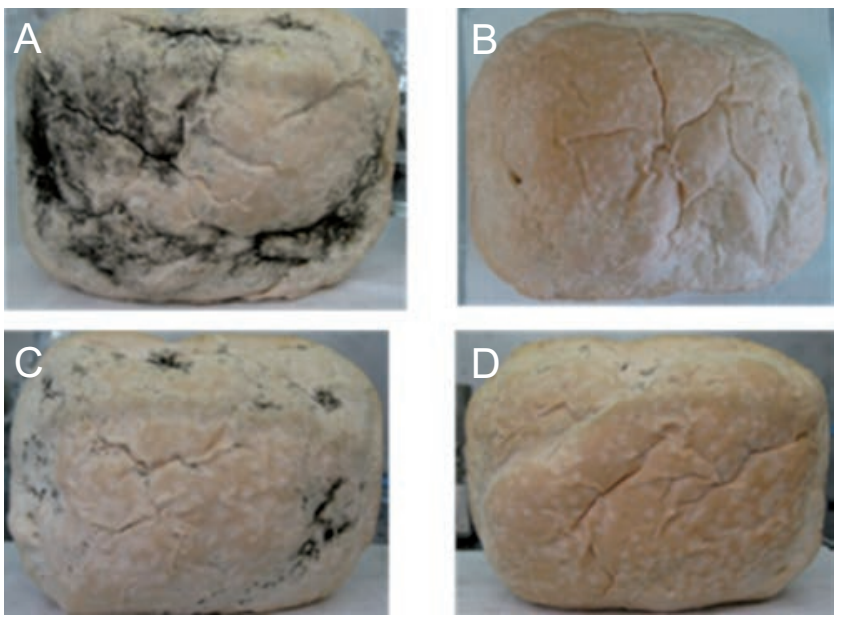

Figure 1. A. niger ITEM5132 growth on the surface of yeast-leavened pan bread containing water $(A)$ and calcium propionate $(0.3 \% \mathrm{w} / \mathrm{w}$ flour) (B) as controls and containing the selected $L$. brevis-based bioingredient $\operatorname{LbBio} 2$ (c) and its ultrafiltrated fraction R30 (D). Loaves were incubated at $25^{\circ} \mathrm{C}$ and examined after 6 days. 
vation of food systems has recently led to the development of new natural antimicrobial compounds having different origins. A variety of systems to prevent food spoilage have been investigated mainly because of the consumers demand for natural products instead of chemicals such as food preservatives (Gray and Bemiller, 2003). The current study confirmed the antifungal properties of LAB bioingredients indicating a synergistic role of organic acids (mainly phenyllactic) and proteinaceous compounds in their efficacy, as also previously suggested (Lavermicocca et al., 2000; Gerez et al., 2010; Black et al., 2013; Ryu et al., 2014; Ryan et al., 2011). In addition the influence of the carbon source or acid precursors on the organic acid production by a selected Lactobacillus brevis strain was demonstrated. In particular, the presence of fructose and maltose in a flour-based medium allowed to obtain a bioingredient (LbBio2) with interesting antifungal performance observed both in in vitro and in bread-making trials. The influence of the carbon source on the antifungal performances of lactic acid bacteria has also been reported by Rouse et al. (2008) who demonstrated that the antifungal activity of the LAB strains tested ( $L$. plantarum, Weissella confusa, W. cibaria, Pediococcus pentosaceus) against Penicillium notatum varied depending from the carbon source used. Authors found a relationship between the growth conditions and the antifungal properties which were only partially due to the organic acid content. Actually, the LbBio2 was characterised by the simultaneous presence of both PLA and OH-PLA, by the higher total organic acid content and the lower $\mathrm{pH}$ value, thus confirming the role of acid compounds in the antifungal efficacy as also demonstrated by Valerio et al. (2009). Authors identified three strains (Weissella cibaria, Leuconostoc citreum and Lactobacillus rossiae) whose fermentation products showed a strong inhibitory activity against $A$. niger isolated from bakery products and were characterised by low $\mathrm{pH}$ values and high content of lactic and acetic acids. As a results, the $\mathrm{pH}$ dependent effectiveness of many anti-fungal compounds (Suhr and Nielsen, 2004), was also observed for LbBio2 bread produced in Test 1 which showed to the lower bread $\mathrm{pH}$ and an appreciable antifungal activity. When the selected

Table 4. Aspergillus niger ITEM5132 growth inhibition caused by $\mathrm{R} 30$-LbBio2 fractions obtained by gel filtration.

\begin{tabular}{lc} 
Sample & Growth inhibition (\%) \\
F7 & 99.6 \\
F8 & 100 \\
\hline F9 & 100 \\
F10 & 100 \\
\hline F11 & 75.8 \\
F12 & 98.3 \\
\hline F13 & 31.08 \\
F14 & - \\
\hline F15 & - \\
F16 & - \\
\hline F17 & - \\
F18 & - \\
\hline F19 & - \\
F20 & - \\
\hline F21 & 47.4 \\
F22 & 51.0 \\
\hline F23 & 49.7 \\
F24 & 60.1 \\
\hline
\end{tabular}

LbBio2 was separated by ultrafiltration to deeper investigate the possible presence of other active metabolite other than organic acids, interestingly the activity was retained in the fraction containing molecules with size higher than $30 \mathrm{kDa}$. These results suggested that the antifungal activity observed in LbBio2 could be attributed to the pool of metabolites produced by the $L$. brevis strain including proteinaceous compounds in agreement with other authors (Corsetti et al., 1998; Niku-Paavola et al., 1999; Ryan et al., 2011; Gerez et al., 2013; Atassanova et al., 2003; Falguni et al., 2010). In particular, Falguni et al. (2010) selected a $L$. brevis strain for its antifungal activity and they demonstrated the proteinaceus nature of the active substances and their molecular weight ranged from $1 \mathrm{kDa}$ to $5 \mathrm{kDa}$. Actually, the involvement of small peptides in the inhibition of mould growth has been widely demonstrated (Schnürer and Magnusson, 2005) while there are few evidences on the role of larger protein compounds in the antifungal activity of LAB. However, Atanassova et al. (2003) demonstrated the production of a protein with molecular mass of about $45 \mathrm{kDa}$ by a $L$. paracase $i$ subsp. paracase $i$ strain which showed bactericidal and fungistatic activities. In the current study, results obtained by the SDSPAGE microfluidic analysis indicated the presence of a protein with molecular mass of about $56 \mathrm{kDa}$ acting in a synergistic way with organic acids. The use of bioingredients to prevent the microbial contamination can be an efficient approach to limit the use of chemical preservatives also in yeast-leavened bread within the hurdle technologies. Further studies are required to identify the metabolites involved in the anti-fungal activity of $L$. brevis ITM18 and to examine in depth the antifungal synergistic activities between organic acids and peptides.

\section{References}

Atanassova M, Choiset M, Dalgalarrondo M, Chobert J-M, Dousset X, Ivanova I, Haertlé T, 2003. Isolation and partial biochemical characterization of a proteinaceous anti-bacteria and anti-yeast compound produced by Lactobacillus paracasei subsp. paracasei M3. Int. J. Food Microbiol. 87:63-73.

Axelsson L, 1990. Lactobacillus reuteri a member of the gut bacterial flora. Ph.D. Thesis, Swedish University of Agricultural Sciences, Uppsala, Sweden.

Black BA, Zannini E, Curtis JM, Gänzle MG, 2013. Antifungal hydroxylfatty acids produced during sourdough fermentation: microbial and enzymatic pathways, and antifungal activity in bread. Appl. Environ. Microb. 79:1866-1873.

Bradford MM, 1976. A rapid and sensitive method for the quantitation of microgram quantities of protein utilizing the principle of protein-dye binding. Anal. Biochem. 72:248-254.

Corsetti A, Gobbetti M, Rossi J, Damiani P, 1998. Antimould activity of sourdough lactic acid bacteria: identification of a mixture of organic acids produced by Lactobacillus sanfrancisco CB1. Appl. Microbiol. Biot. 50:253-6.

Dal Bello F, Clarke CI, Ryan LAM, Ulmer H, Schober TJ, Ström K, 2007. Improvement of the quality and shelf life of wheat bread by fermentation with the antifungal strain Lactobacillus plantarum FST 1.7. J. Cereal Sci. 45:309-18.

European Commission, 1995. European Parliament and Council Directive No. 95/2/EC of 20 February 1995 on food additives other than colours and sweeteners. In: Official Journal L 61, 18/3/1995, p. 53.

Falguni P, Shilpa V, Mann B, 2010. Production of proteinaceous antifungal substances from Lactobacillus brevis NCDC 02 . Int. J. Dairy Technol. 63:70-6.

Filtenborg 0, Frisvad JC, Thrane U, 1996. Moulds in food spoilage. Int. J. Food Microbiol. 33:85-102. 
Gerez CL, Torino MI, Obregozo MD, Font de Valdez G, 2010. A ready-touse antifungal starter culture improves the shelf-life of packaged bread. J. Food Protect. 4:758-62

Gerez CL, Torino MI, Rollán G, Font de Valdez G, 2009. Prevention of bread mould spoilage by using lactic acid bacteria with antifungal properties. Food Control. 20:144-8.

Gerez CL, Torres MJ, Font de Valdez G, Rollán G, 2013. Control of spoilage fungi by lactic acid bacteria. Biol. Control 64:231-7.

Gray JA, Bemiller JN, 2003. Bread staling: molecular basis and control. Compr. Rew. Food Sci. F. 2:1-21.

Guyonot ME, Ramos AJ, Sanchis V, Marín S, 2005. Study of benzoate, propionate and sorbate salts as mould spoilage inhibitors on intermediate moisture bakery products of low pH (4.5-5.5). Int. J. Food Microbiol. 101:161-8.

Karin IS, Per VN, 2005. Inhibition of fungal growth on wheat and rye bread by modified atmosphere packaging and active packaging using volatile mustard essential oil. J. Food Sci. 70:M37-44.

Katina K, Sauri M, Alakomi H-L, Mattila-Sandholm T, 2002. Potential of lactic acid bacteria to inhibit rope spoilage in wheat sourdough bread. Food Sci. Technol. 35:38-45.

Komleni DK, Ugar i -Hardi Ž, Juki M, Planini M, Buci -Koji A, Strelec I, 2010. Wheat dough rheology and bread quality effected by Lactobacillus brevis preferment, dry sourdough and lactic acid addition. Int. J. Food Sci. Tech. 45:1417-25.

Latgè JP, Paris S, 1991. The fungal spore-reservoir of allergens. In: G.T. Cole, H.C. Hoc (eds.), The fungal spore and disease initiation in plants and animals. Plenium Press, New York, USA, pp 379-401.

Lavermicocca P, Valerio F, Evidente A, Lazzaroni S, Corsetti A, Gobbetti $\mathrm{M}, 2000$. Purification and characterization of novel antifungal compounds from the sourdough Lactobacillus plantarum strain 21B. Appl. Environ. Microb. 66:4084-90.

Lavermicocca P, Valerio F, Visconti A, 2003. Antifungal activity of phenyllactic acid against molds isolated from bakery products. Appl. Environ. Microb. 69:634-40.

Legan JD,1993. Mould spoilage of bread: the problem and some solutions. Int. Biodeter. Biodegr. 32:33-53.

Legan JD, Voysey PA, 1991. Yeast spoilage of bakery products and ingredients. J. Appl. Bacteriol. 70: 361-71.

Magnusson J, Schnürer J, 2001. Lactobacillus coryniformis subsp. coryniformis strain $\mathrm{Si} 3$ produces a broad-spectrum proteinaceous antifungal compound. Appl. Environ. Microb. 67:1-5.

Niku-Paavola M, Laitila LA, Mattila-Sandholm T, Hikara A, 1999. New types of antimicrobial compounds produced by Lactobacillus plantarum. J. Appl. Microbiol. 86:29-35.

Pepe 0, Baiotta G, Moschetti G, Greco T, Villani F, 2003. Rope producing strains of Bacillus spp. from wheat bread and strategy for their control by acid lactic bacteria. Trends Food Sci. Tech. 55:319-22.
Rouse S, Harnett D, Vaughan A, van Sinderen D, 2008. Lactic acid bacteria with potential to eliminate fungal spoilage in foods. J. Appl. Microbiol. 104:915-23.

Ryan LAM, Zannini E, Dal Bello F, Pawlowska A, Koehler P, Arendt EK, 2011. Lactobacillus amylovorus DSM 19280 as a novel food-grade antifungal agent for bakery products. Int. J. Food Microbiol. 146:276-83.

Ryu EH, Yang EJ, Woo RE, Chang HC, 2014. Purification and characterization of antifungal compounds from Lactobacillus plantarum HD1 isolated from kimchi. Food Microbiol. 41:19-26.

Schnürer J, Magnusson J, 2005. Antifungal lactic acid bacteria as biopreservatives. Trends Food Sci. Tech. 16:70-8.

Stiles ME, 1996. Biopreservation by lactic acid bacteria. A. van Leeuw. J. Microb. 70:331-45.

Ström K, 2005. Fungal inhibitory lactic acid bacteria - characterization and application of Lactobacillus plantarum MiLAB 393. Ph.D. Thesis, Swedish University of Agricultural Sciences, Uppsala, Sweden.

Ström K, Sjögren J, Broberg A, Schnürer J, 2002. Lactobacillus plantarum MiLAB 393 produces the antifungal cyclic dipeptides cyclo (L-Phe-L-Pro) and cyclo (L-Phe-trans-4-OH-L-Pro) and phenyllactic acid. Appl. Environ. Microb. 68:4322-7.

Suhr KI, Nielsen PV, 2004. Effect of weak acid preservatives on growth of bakery product spoilage fungi at different water activities and pH values. Int. J. Food Microbiol. 95:67-78.

Valerio F, De Bellis P, Di Biase M, Lonigro SL, Giussani B, Visconti A, Lavermicocca P, Sisto A, 2012. Diversity of spore-forming bacteria and identification of Bacillus amyloliquefaciens as a species frequently associated with the ropy spoilage of bread. Int. J. Food Microbiol. 156:278-85.

Valerio F, Di Biase M, Caputo L, Creanza TM, Ancona N, Visconti A, Lavermicocca P, 2014. Effect of Lactobacillus brevis-based bioingredient and bran on microbiological, physico-chemical and textural quality of yeast-leavened bread during storage. Innov. Food Sci. Emerg. 25:2-8.

Valerio F, Favilla M, De Bellis P, Sisto A, De Candia S, Lavermicocca P, 2009. Antifungal activity of strains of lactic acid bacteria isolated from a semolina ecosystem against Penicillium roqueforti, Aspergillus niger and Endomycesfibuliger contaminating bakery products. Syst. Appl. Microbiol. 32:438-48.

Visconti A, Bottalico A, 1983. High level of Ocratoxins A and B in moldy bread responsible for mycotoxicosis in farm animals. J. Agr. Bacteriol. 31:1122-3.

Wehrle K, Grau H, Arendt EK, 1997. Effects of lactic acid, acetic acid and table salt on fundamental rheological properties of wheat dough. Cereal Chem. 74:739-44. 